\title{
Atypical Presentation of Lateral Periodontal Cyst in an Elderly Female Patient - A Rare Case Report
}

\author{
Renita Lorina Castelino, Kumuda Rao, Supriya Bhat, Subhas Gogineni Babu \\ Department of Oral Medicine and Radiology, A B Shetty Memorial Institute of Dental Sciences, Nitte \\ University, Mangalore 575018, India \\ Correspondence e-mail to: renita.castelino@yahoo.com
}

\begin{abstract}
The lateral periodontal lateral cyst (LPC) is an uncommon developmental odontogenic cyst defined as a radiolucent lesion which develops along the lateral aspect of an erupted vital tooth. LPC represents approximately $0.8 \%$ to $2 \%$ of all odontogenic cysts. The most frequently reported location of a lateral periodontal cyst is the mandibular caninepremolar area, followed by the anterior region of the maxilla. The lateral periodontal cyst is usually asymptomatic and presents as a round, oval or teardrop-like well-circumscribed inter-radicular radiolucent area, usually with a sclerotic margin lying between the apex and cervical margin of the teeth. The lateral periodontal cyst usually is seen in the fifth to sixth decade of life with a male preponderance. This paper reports an atypical case of an inter-radicular radiolucent cystic lesion in located between the mandibular central incisor and the canine area in an 87-year-old female patient mimicking clinically and radiographically as a residual cyst but histopathologically confirmed as a lateral periodontal cyst.
\end{abstract}

Key words: elderly, lateral periodontal cyst, odontogenic cyst, residual cyst

\section{INTRODUCTION}

Odontogenic cysts are classified as inflammatory and developmental according to their epithelial lining by the World Health Organization in 1992 and since then lateral periodontal cysts (LPC) have been regarded as an independent condition. ${ }^{1}$ The LPC is a developmental odontogenic cyst which develops along the lateral aspect of an erupted vital tooth. ${ }^{2}$ LPC is mostly prevalent in adults in the 5 th -7 th decades, with a mean age of 52 years, with a male predilection. It is usually associated with a vital tooth unless secondarily infected. The most frequently reported location of LPC is the mandibular premolar area followed by the maxillary anterior region. ${ }^{3}$ They are usually less than $1 \mathrm{~cm}$ in diameter. LPC is one of the cysts of lower incidence among the developmental odontogenic cysts. $^{3}$ They are usually found on routine radiographic investigations unless secondarily infected. The case presented here reports of a symptomatic unusual lateral periodontal cyst in an anterior edentulous area in an elderly woman mimicking a residual cyst clinically and radiologically.

\section{CASE REPORT}

An 87-year-old female patient reported to the Department of Oral Medicine and Radiology with the complaint of swelling in the lower front region of the jaw since one month before the report (Figure 1). The swelling was initially large in size but had considerably reduced when the patient reported to us as told by the patient. The swelling was non-tender and the patient reported of occasional fluid oozing out of the swelling. The patient's medical and drug history was non-contributory. On general examination the patient was of thin built and poorly nourished. On intraoral examination, a well-defined swelling was noted on the lower front edentulous region measuring approximately $2 \times 2 \mathrm{~cm}$ in size extending anteriorly from the mesial surface of 42, posteriorly till the mesial surface of 44, superiorly up to the alveolar crest and inferiorly up to the vestibular region. The surface of the swelling was bluish black in colour in the middle. On palpation, the observative findings were confirmed, and the swelling was soft and fluctuant indicating perforation of the buccal cortical plate (Figure 1). The edentulous space 


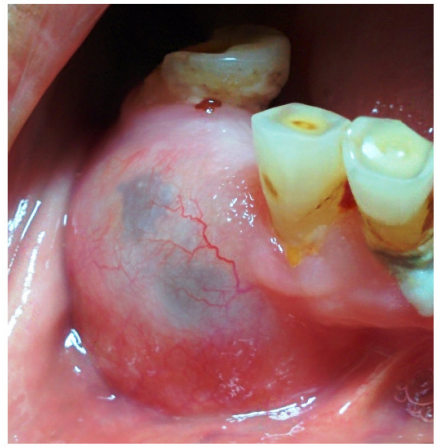

Figure 1. Clinical photograph of the swelling, showing a well-defined bluish swelling on the lower right edentulous region

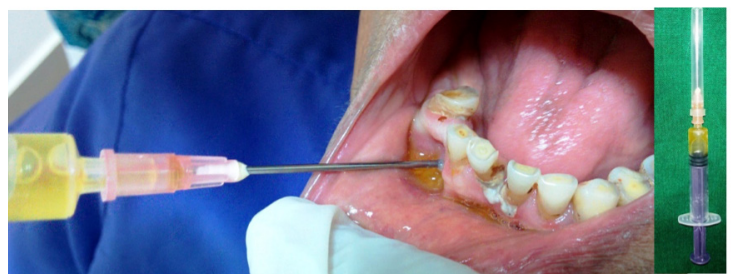

Figure 2. Aspiration yielding straw colored fluid

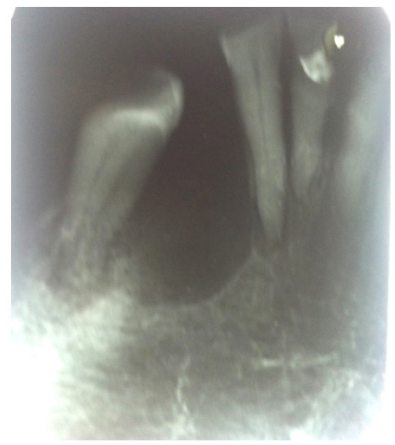

Figure 3. Intra oral periapical radiograph showing round shaped radioluscency between 42 and 44

was created post extraction five years back. There was no swelling reported during the time of extraction. There was no swelling seen on the lingual aspect. The patient also had multiple missing teeth and generalised attrition and periodontitis. Based on the history and clinical findings a provisional diagnosis of a residual cyst with respect to 43 was made. The other differential diagnoses which were considered were radicular cyst and lateral periodontal cyst. As a part of chair side investigations, aspiration was performed which yielded a straw colored fluid (Figure 2). An intraoral periapical radiograph showed a well-circumscribed oval shaped inter-radicular radiolusency surrounded by a thin sclerotic border measuring approximately $2 \mathrm{~cm}$ in diameter between 42 and 44 (Figure 3). The internal of the radiolucency was clear with no opacification. The long axis of the 44 was drifted mesially towards the radiolucency. The orthopantomogram also

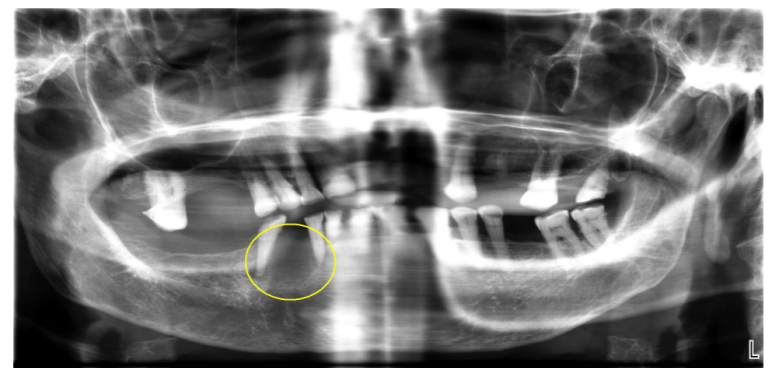

Figure 4. Orthopantomogram showing round shaped radioluscency between 42 and 44

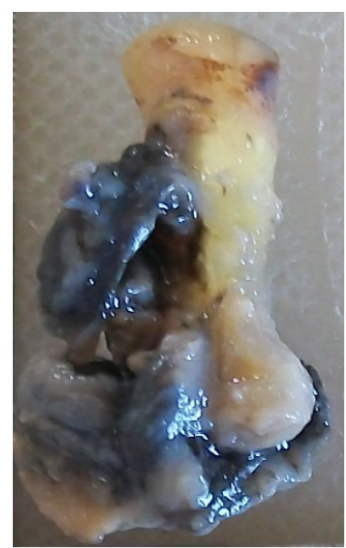

Figure 5. Gross specimen of the cyst attached to the tooth

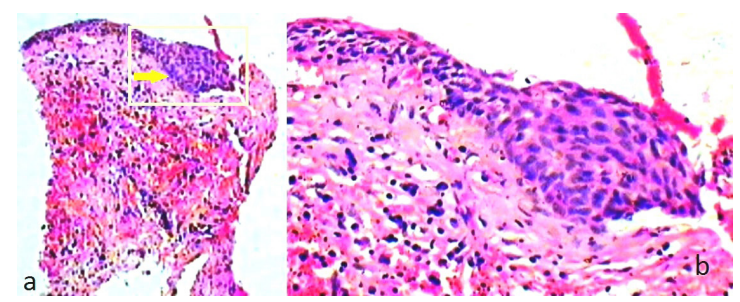

Figure 6. a. Low power histopathologic sections of LPC; b. High power histopathologic section of LPC

revealed the round shaped radiolucency measuring approximately around $2 \times 2 \mathrm{~cm}$ in size between the roots of 42 and 43 (Figure 4). As a part of treatment, the cyst was surgically enucleated along with the tooth and was sent for histopathologic examination (Figure 5). The histopathological section stained with $\mathrm{H}$ and E showed epithelium, connective tissue and capsule. The epithelium was stratified squamous and nonkeratinized type and focal epithelial plaque-like areas were seen along the epithelial lining. The connective tissue capsule was composed of a dense chronic inflammatory cell infiltrate mainly comprising of lymphocytes and plasma cells. The bundles of collagen fibres and fibroblasts, blood vessels and plenty of RBC's were also seen. The histopathological diagnosis of LPC was made (Figure 6). The patient was advised total extraction followed by prosthodontic rehabilitation and is currently kept on a regular follow up. 


\section{DISCUSSION}

The lateral periodontal cysts are defined as nonkeratinized and non-inflammatory developmental cysts located adjacent or lateral to the root of a vital tooth. ${ }^{4}$ The lateral periodontal cyst (LPC) is a developmental odontogenic cyst with an unclear aetiology. ${ }^{5}$ A number of theories have been suggested to explain the development and formation of LPC which could originate from any early dentigerous cyst which remains after tooth eruption, a primordial cyst, cell rests of Malassez, reduced enamel epithelium and remnants of the dental lamina. ${ }^{6}$ At present the theory put forth by Wysocki and his colleagues is the most accepted one which suggests the histogenesis of LPC from postfunctional dental lamina rest cells. ${ }^{7}$ LPC is an uncommon lesion representing approximately $0.8 \%$ to $2 \%$ of all odontogenic cysts. ${ }^{8}$ LPC is seen typically along the lateral surface of a tooth..$^{9}$ They have a high site predilection for inter-radicular areas and the mandibular canine-premolar region followed by the maxillary anterior region. ${ }^{6}$ In the case presented here, the cyst was found in between the mandibular lateral incisor and the premolar with canine being missing. LPC is predominantly seen among males in their fifth or sixth decades of life. ${ }^{10}$ The case reported here is of an elderly female patient of ninth decade which is unusual. The name reflects their position. They arise from the periodontium and extend into the interproximal bone in between the apex and alveolar crest next to a vital tooth. ${ }^{6}$ The multilocular and polycystic variant of LPC is termed as Botryoid cyst which was first described in 1973 by Weathers and Waldron. ${ }^{6}$ The clinical manifestations usually are mild and are found on routine radiographic investigation which reveals a round or tear drop shaped radiolucent area surrounded by a sclerotic border less than $1 \mathrm{~cm}$ in size in most of the cases..$^{10}$ The case presented here measured around $2 \mathrm{~cm}$ in size surrounded by a hyperostotic border. The case presented here was symptomatic with a clinical swelling measuring around $2 \mathrm{~cm}$ in diameter. The teeth associated with LPC are usually vital but the teeth in the case presented here were non vital. The clinical and radiographic characteristics per se are not as distinctive as the diagnostic criteria for a diagnosis of lateral periodontal cyst. ${ }^{6}$ The WHO "Histological typing of odontogenic tumours" has more or less changed the lateral periodontal cyst from a clinicoradiological entity into a histopathological one and today the diagnosis of lateral periodontal cyst is primarily based on histopathologic features. ${ }^{6}$

The differential diagnoses of LPC include gingival cyst, lateral radicular cyst, lateral (inflammatory) periodontal cyst, odontogenic keratocyst, radiolucent odontogenic tumors, and benign mesenchymal tumors. ${ }^{6}$
The recurrence is usually rare in LPC. The surgically excised tissues must be thoroughly evaluated, due to a rare case reported of well-differentiated squamous cell carcinoma arising in the epithelial lining of a LPC." The treatment of choice according to all authors is surgical enucleation of the cyst. ${ }^{1,6}$

\section{CONCLUSION}

In conclusion, lateral periodontal cyst is an uncommon developmental cyst arising from the lateral aspect of the tooth. The case presented here is unique and unusual as the cyst was present in an elderly woman which clinically and radiologically mimicked a residual cyst.

\section{REFERENCES}

1. Balan P, Babu SG, Shetty SR, Dsouza D. Lateral periodontal cyst- A report of two cases with varying clinico-radiological features. J Interdiscipl Histopathol. 2012;1:41-4.

2. Valério GM, Cury RM. Diagnosis and treatment of lateral periodontal cyst: Report of three clinical cases. Rev Odontociênc. 2009;24:213-7.

3. De Carvalho LF das C e S, Lima CF, Cabral LAG, Brandão AAH, Almeida JD. Lateral periodontal cyst: A case report and literature review. J Oral Maxillofac Res. 2010;1:e5.

4. Kramer IRH, Pindborg JJ, Shear M. WHO Histological Typing of Odontogenic Tumours. 2nd ed. Geneva: Springer-Verlag; 1992. p. 34-118.

5. Wood KN, Goaz PW. Differential diagnosis of oral and maxillofacial lesions. 5th ed. St. Louis: Mosby; 1997. p. 305-6.

6. Rao KA, Shetty SR, Babu SR. Unuual clinicoradiographic presentation of lateral periodontal cyst. Journal of Dentistry TUMS. 2012;9:265-9.

7. Shafer WG, Hine MK, Levy BM. A Textbook of Oral Pathology. 3rd ed. Saunders, Philadelphia, USA; 1974. p. 243-5.

8. Altini M, Shear M. The lateral periodontal cyst: An update. J Oral Pathol Med. 1992;21:245-50.

9. Neville BW, Damn DD, Allen CM, Bou-quot JE. Oral and maxillofacial pathology. 3rd ed. St. Louis, Missouri: Elsevier; 2009. p. 692-5.

10. Formoso-Senande MF, Figueiredo R, Berini-Aytés L, Gay-Escoda C.Lateral periodontal cysts: A retrospective study of 11 cases. Med Oral Patol Oral Cir Bucal. 2008;13:E313-7.

11. Baker RD, D'Onofrio ED, Corio RL, Crawford BE, Terry BC. Squamous cell carcinoma arising in a lateral periodontal cyst. Oral Surg Oral Med Oral Pathol. 1979;47:495-9. 